\title{
Performance Evaluation of the Abbott Alinity hs Blood Slide Maker/Stainer
}

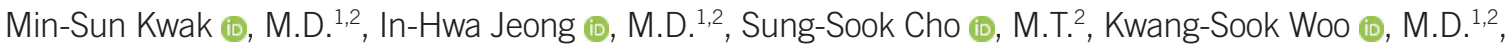 \\ and Jin-Yeong Han (), M.D. ${ }^{1,2}$ \\ ${ }^{1}$ Department of Laboratory Medicine, Dong-A University College of Medicine, Busan, Korea; ${ }^{2}$ Department of Laboratory Medicine, Dong-A University Hospital, \\ Busan, Korea
}

\section{Dear Editor,}

Abbott Laboratories (Abbott Diagnostics, Santa Clara, CA, USA) recently released the Alinity h-series for high-throughput, automated hematology analysis $[1,2]$. Since the introduction of automated slide makers and stainers in the late 1970s, only a few studies have evaluated the performance of automated slide makers [3-6]. We evaluated the performance of the Abbott Alinity hs automated slide maker and stainer and compared the white blood cell (WBC) differential counts between slides prepared with Alinity hs and manual smears. The Institutional Review Board of Dong-A University Hospital, Busan, Korea, approved this study (DAUHIRB-19-194).

Peripheral blood specimens from 50 healthy controls and 115 patients referred to the Department of Laboratory Medicine, Dong-A University Hospital between September 2019 and February 2020 were collected in K3-EDTA VACUETTE blood collection tubes (Greiner Bio-One GmbH, Kremsmunster, Austria). We included at least one third to half the total number of abnormal (patient) specimens, as suggested by the CLSI and International Council for Standardization in Hematology guidelines [7, 8]. The blood specimens were processed within four hours of phlebotomy, and the residuals after laboratory tests were used for the study.

All automated complete blood cell count (CBC) and WBC dif- ferential counts were obtained using the Abbott Alinity hq analyzer. We analyzed the blood smear quality, repeatability, and cellular carry-over and compared WBC differential counts with those obtained using manual smears [7, 8]. Both Alinity hs and manual smears were stained using Abbott Wright-Giemsa staining reagents and the Alinity hs stainer [1]. Statistical analyses were performed using MedCalc (version 14.8.1; MedCalc Software Ltd., Ostend, Belgium) and EP Evaluator Release 11 (Data Innovation LLC, South Burlington, VT, USA). Agreement and the interpretation criteria were adapted from the manufacturer's acceptance limits and state-of-the-art criteria [1, 7].

Macroscopic examination revealed that all 165 Alinity hs smears showed an acceptable quality in terms of length, margins, and thickness, with a smooth and gradual transition from thick to thin. When the grading scheme was applied, all 50 normal (100\%) and 107 abnormal (93.0\%) specimens were graded as "slight precipitation." Six (5.2\%) and two (1.7\%) abnormal specimens showed moderate and heavy precipitation, respectively; however, all specimens were judged acceptable for morphological assessment and WBC differential count.

The distribution of monocytes between the margins and body of the smears was assessed in 50 normal and 106 abnormal specimens with a total WBC count $>3 \times 10^{9} / \mathrm{L}$ (which is above the reference range, $3,000-9,300 \times 10^{9} / \mathrm{L}$, used in the labora-
Received: August 23, 2021

Revision received: September 14, 2021

Accepted: January 18, 2022

Corresponding author: Jin-Yeong Han M.D., Ph.D.

Department of Laboratory Medicine, Dong-A University College of Medicine, 26 Daesingongwon-ro, Seo-gu, Busan 49201, Korea

Tel: +82-51-240-5323, Fax: +82-51-255-9366, E-mail: jyhan@dau.ac.kr

\section{(c) (1) $(9$}

(C) Korean Society for Laboratory Medicine

This is an Open Access article distributed under the terms of the Creative Commons Attribution Non-Commercial License (https://creativecommons.org/licenses/by-nc/4.0) which permits unrestricted non-commercial use, distribution, and reproduction in any medium, provided the original work is properly cited. 
tory). In all normal (100\%) and 104/106 abnormal (98.1\%) specimens, the number of monocytes in the margins did not exceed that in the body of the smear by $>2-3$ times, which is regarded acceptable $[4,5]$. Nine abnormal specimens showed

Table 1. Repeatability based on five abnormal (patient) specimens with normal $\mathrm{CBC}$ results

\begin{tabular}{lccc}
\hline & $\begin{array}{c}\text { Neutrophils (\%) } \\
(\text { mean } \pm \text { SD) }\end{array}$ & $\begin{array}{c}\text { Lymphocytes (\%) } \\
(\text { mean } \pm \text { SD) }\end{array}$ & $\begin{array}{c}\text { Monocytes (\%) } \\
(\text { mean } \pm \text { SD) }\end{array}$ \\
\hline Specimen 1 & $71.4 \pm 1.7$ & $23.7 \pm 1.4$ & $4.3 \pm 1.0$ \\
Specimen 2 & $66.9 \pm 2.1$ & $24.0 \pm 1.7$ & $6.3 \pm 0.9$ \\
Specimen 3 & $61.0 \pm 2.9$ & $29.2 \pm 2.4$ & $7.1 \pm 1.9$ \\
Specimen 4 & $69.4 \pm 2.3$ & $27.7 \pm 2.6$ & $1.6 \pm 0.6$ \\
Specimen 5 & $71.8 \pm 1.8$ & $20.5 \pm 1.8$ & $4.5 \pm 1.2$ \\
\hline
\end{tabular}

Abbreviation: $\mathrm{CBC}$, complete blood cell count.

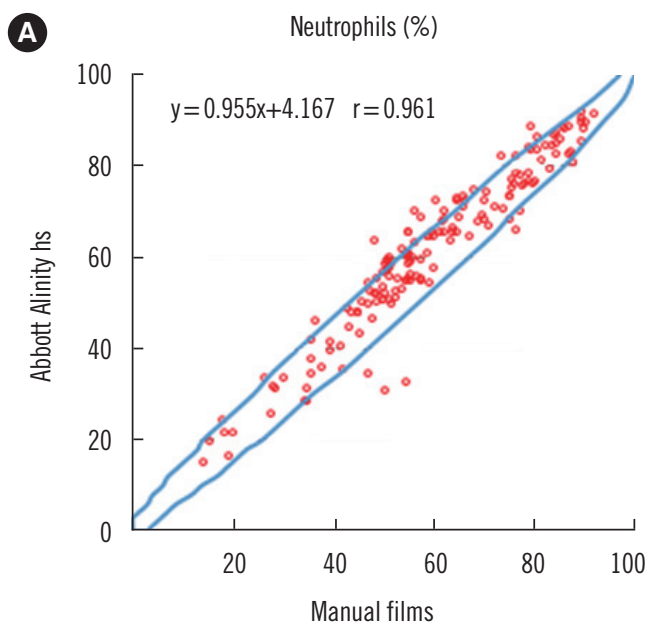

a WBC count $<3 \times 10^{9} / \mathrm{L}$ (below the lower reference intervals) and were excluded from the analysis.

We examined repeatability using 10 blood smears prepared from five normal blood specimens with the Alinity hs, using a manual 200-cell WBC differential count. All smears showed acceptable SD values ranging 1.7-2.9 for neutrophils, 1.4-2.6 for lymphocytes, and 0.6-1.9 for monocytes (Table 1) [4].

Two specimens with numerous smudge cells (100 smudge cells on average based on the 200-cell differential count) and leukemic promyelocytes (98.7\% promyelocytes on average based on the 200-cell differential count) showed no specific smudge or promyelocytic cells, respectively, in three high-low runs.

The size, shape, $\mathrm{Hb}$ stainability, and distribution of red blood cells were comparable between Alinity hs and manual smears

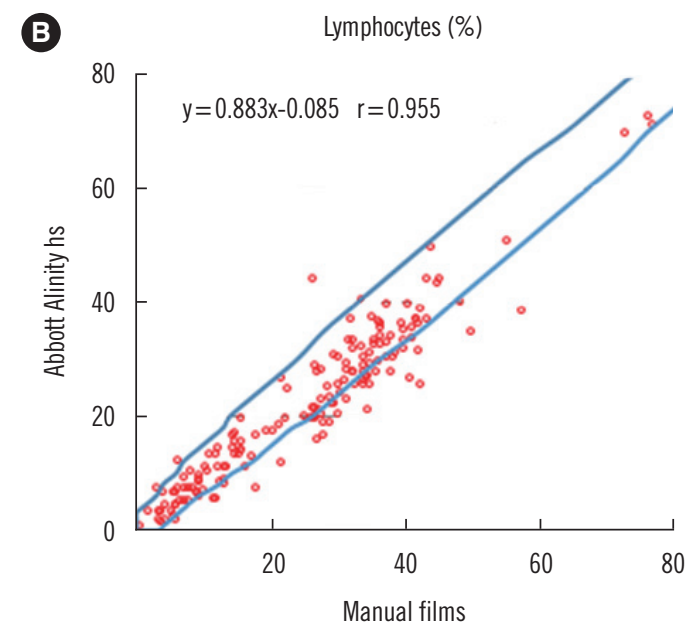

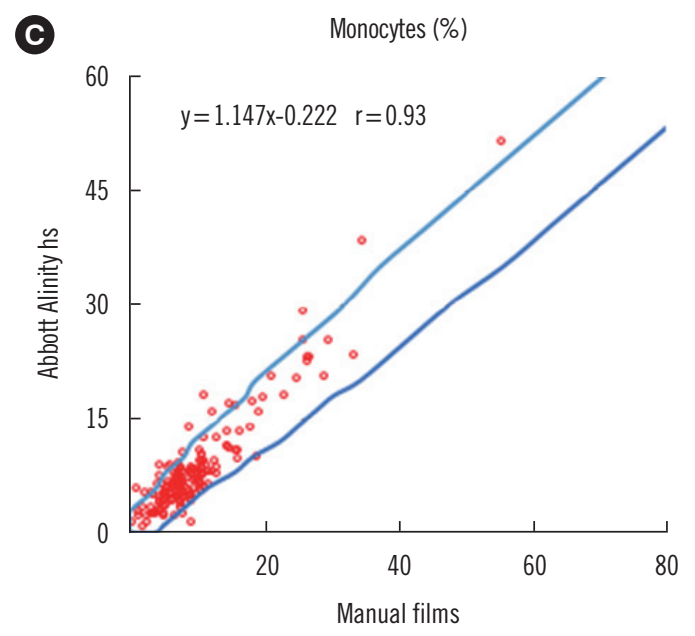

Fig. 1. Comparison of 400-cell WBC differential count results between Abbott Alinity hs and manual smears. (A) Neutrophils, (B) Lymphocytes, (C) Monocytes. Blue lines indicate 95\% confidence intervals.

Abbreviation: WBC, white blood cell. 
in all the 50 normal and 115 abnormal blood specimens evaluated. Morphological assessment revealed that platelet size, granularity, and the presence of clumps were also comparable.

A 400-cell WBC differential count by two examiners revealed a remarkable accordance between Alinity hs and manual smears for the major WBC types (Fig. 1). Correlations in the neutrophil, lymphocyte, and monocyte percentages between hs and manual smears were excellent, with a correlation coefficient (r) of 0.961, 0.955, and 0.93, respectively. Eosinophils and basophils showed excellent or moderate correlation between hs and manual smears, with $r$ of 0.934 and 0.684 , respectively (data not shown), in normal and abnormal specimens.

Even in the era of digital morphology, slide makers and stainers have not been thoroughly evaluated for performance [7, 9]. To the best of our knowledge, this was the first comprehensive evaluation of the Abbott Alinity hs slide maker and stainer. The results demonstrate that the systems perform well in terms of blood smear quality, repeatability, and cellular carry-over and that comparable results with manual smears in routine laboratory work for major WBC differential counts.

\section{ACKNOWLEDGEMENTS}

We thank Abbott Diagnostics and Abbott Korea Ltd. for technical support for the design of the study.

\section{AUTHOR CONTRIBUTIONS}

Han JY and Cho SS analyzed the manual WBC differential counts. Woo KS performed the statistical analysis. Jeong $\mathrm{IH}$ and Kwak MS contributed to data collection and manuscript writing along with Han JY. All authors contributed to the study design and revised and approved the final manuscript.

\section{CONFLICTS OF INTEREST}

The authors declare no conflict of interests.

\section{RESEARCH FUNDING}

This work was supported by the Dong-A University research fund (Han JY).

\section{ORCID}

Min-Sun Kwak https://orcid.org/0000-0001-6042-6976

In-Hwa Jeong

Sung-Sook Cho https://orcid.org/0000-0001-8383-8228 https://orcid.org/0000-0001-9932-7908 Kwang-Sook Woo Jin-Yeong Han https://orcid.org/0000-0002-3674-8534 https://orcid.org/0000-0003-0280-2739

\section{REFERENCES}

1. Woo KS, Jeong IH, An GD, Lim HH, Han JY. Performance evaluation of new Abbott Alinity hq hematology analyzer. Int J Lab Hematol 2019; 41:657-63.

2. Van der Beken Y, Van Dalem A, Van Moer G, Segers E, Damiaens S, Hoffmann J, et al. Performance evaluation of the prototype Abbott Alinity hq hematology analyzer. Int J Lab Hematol 2019;41:448-55.

3. La Gioia A, Fumi M, Pezzati P, Balboni F, Pancione Y, Rocco L, et al. Automatic wedge smears preparation may cause traumatic morphological changes in peripheral blood cells. J Clin Pathol 2018;71:168-71.

4. Brown W, Keeney M, Hedley BD. Initial performance evaluation of the UniCel ${ }^{\circledR}$ DxH slide maker/stainer Coulter ${ }^{\circledR}$ cellular analysis system. Int J Lab Hematol 2014;36:172-83.

5. Simson E, Gascon-Lema MG, Brown DL. Performance of automated slidemakers and stainers in a working laboratory environment-routine operation and quality control. Int J Lab Hematol 2010;32:e64-76.

6. de Bitencourt ED, Voegeli CF, Onzi Gdos S, Boscato SC, Ghem C, Munhoz T. Validation of the Sysmex sp-1000i automated slide preparerstainer in a clinical laboratory. Rev Bras Hematol Hemoter 2013;35: 404-8.

7. International Council for Standardization in Haematology, Writing Group; Briggs C, Culp N, Davis B, d'Onofrio G, Zini G, et al. ICSH guidelines for the evaluation of blood cell analysers including those used for differential leucocyte and reticulocyte counting. Int J Lab Hematol 2014;36: 613-27.

8. CLSI. H2O-A2: Reference leukocyte (WBC) differential count (proportional) and evaluation of instrumental methods. 2nd ed. Wayne, PA: Clinical Laboratory Standards Institute, 2007.

9. Kim HN, Hur M, Kim H, Park M, Kim SW, Moon HW, et al. Comparison of three staining methods in the automated digital cell imaging analyzer Sysmex DI-60. Clin Chem Lab Med 2018;56:e280-3. 